\title{
Relationship between upper extremity fat mass and race time in triathlete
}

\author{
Ebru CETIN 1, Ulviye BILGIN 1, Mergul COLAK ${ }^{2}$, Imdat YARIM ${ }^{1}$, Halil TASKIN ${ }^{3}$ \\ ${ }^{1}$ Faculty of Sport Sciences Gazi University, Ankara, Turkey \\ ${ }^{2}$ School of Physical Education and Sports, Erzincan University, Erzincan, Turkey \\ ${ }^{3}$ Faculty of Sport Sciences, Selçuk University, Konya, Turkey \\ Address Correspondence to U. Bilgin, e-mail: ulviye@gazi.edu.tr
}

\begin{abstract}
This study was conducted to investigate the effect of upper extremity fat ratio on triathletes' the race time. 43 volunteer athletes who participated in the $9^{\text {th }}$ World University Triathlon Championship ((17 women -26 men), age $22.30 \pm 2.42$ years, height $172.76 \pm 16.08 \mathrm{~cm}$, body weight $64.79 \pm 9.93 \mathrm{~kg})$ ) participated in the study. Segmental analysis was performed by Tanita BC 418 Body Composition Analyzer before the race, on an empty stomach and with shorts and T-shirt. At $40{ }^{\circ} \mathrm{C}$ air temperature, athletes firstly swam for $1.5 \mathrm{~km}$, which was followed by cycling on $40 \mathrm{~km}$ track and finally 10 kilometers track run. SPSS 16.0 statistical software was utilized for data calculation and evaluation. According to the normality test results; Pearson correlation analysis was used to explain the relationship between the measurements and linear regression analysis was utilized to determine the effect of fat ratio on race time. This study in which the effect of upper extremity fat ratio on race time was examined, revealed that upper extremity segmental analysis has no significant effect on swimming time in triathlon $(\mathrm{p}>0.05)$. In addition; upper extremity fat mass has no significant effect on jogging, cycling and total race time either ( $p>0.05)$. Fat percentage is determined to have a significant relationship in positive manner with jogging $(r=0.382)$, cycling $(r=0.370)$, and total race time $(r=0.387)$ at $\mathrm{p}<0.05$ level. Upper extremity lean mass and muscle mass are found to have a significant relationship in negative manner respectively with jogging $(r=-0.475, r=-0.472)$, cycling $(r=-0.738, r=-$ $0.735)$ and total race time $(r=-0.664, r=-0.661)$ at $\mathrm{p}<0.001$ level. As a result, it was observed that the upper extremity fat mass is not associated with jogging, cycling, swimming and total race time, on the other hand upper extremity muscle and lean mass are found to be more effective on race time as compared to fat percentage. As the upper extremity, lean mass and muscle mass increases, total race time of athletes shortens and accordingly their performance are likely to be affected in a positive manner.
\end{abstract}

Keywords: Upper extremity, fat ratio, triathlon, race time.

\section{INTRODUCTION}

It is stated that the ideal body composition and anthropometric characteristics required to participate in competitive sports vary as a function of the sports or the competition $(7,9,15,28,31)$. Thus, it is also reported that the athletes should have suitable anthropometric and physiological characteristics in order to improve their performances (19). It is observed that the effects of anthropometric characteristics on exercise performance of the athletes in endurance sports, such as triathlon, have been investigated in previous studies conducted on long-distance and marathon runners (1). It is reported that the body fat ratio is related to the performance in female marathon runners (11), male ultra-marathon runners (14), and female swimmers $(27,30)$. Knechtle et al. (19) reported that the lower fat ratio, length of body segments, and high levels of lean body mass are related to advanced athletic performance in cycling and triathlon. In another research, Siders et al. (27) reported that higher levels of athletic performance are associated with both low body fat ratio and higher levels of lean body mass. In addition, there are many other studies, where the effects of upper arm circumference $(1,16,20,22,29)$, length of upper extremity $(8,16)$, and skinfold thickness (triceps skinfold thickness) $(16,18,19)$ on performance were analyzed in endurance sports, such as running, swimming and triathlon. When the previous studies were reviewed, no specific studies were found on the effect of fat and lean masses of the upper extremity on performance and race time of the triathletes. Thus, this study was conducted to investigate the relationship between the upper extremity fat ratio and triathletes' race time. 


\section{MATERIALS \& METHODS}

Total of 43 volunteer athletes (17 women - 26 men), who were able to complete the race, have participated in this study. The measurements were made in the $9^{\text {th }}$ World University Triathlon Championship in Erdek, Balıkesir. The age, height and body weight averages of the triathletes are respectively $22.30 \pm 2.42$ years, $172.76 \pm 16.08 \mathrm{~cm}$, and $64.79 \pm 9.93 \mathrm{~kg}$. Upper extremity segmental analysis was performed by Tanita BC 418 Body Composition Analyzer before the race, on an empty stomach and with shorts and t-shirts on. The athletes completed the standard triathlon distances at $40^{\circ} \mathrm{C}$ by swimming $1.5 \mathrm{~km}$ (water temperature: $23^{\circ} \mathrm{C}$ ), cycling $40 \mathrm{~km}$ running $10 \mathrm{~km}$.

\section{Statistical Analysis}

SPSS 16.0 statistical software was utilized for data calculation and evaluation. According to the normality test results; Pearson correlation analysis was used to explain the relationship between the measurements. Linear regression analysis was utilized to determine the effects of upper extremity fat and lean mass, fat ratio, and muscle mass on swimming, cycling, running and total race time. significant level was taken as 0.05 .

\section{RESULTS}

When Table 1 is analyzed, a negative and statistically significant relationship between the running time and upper extremity muscle and lean masses, and a positive and statistically significant relationship between the running time and the fat ratio were observed according to the regression analysis results.

When Table 2 is analyzed, it is observed that the effects of the fat and lean masses of upper extremity on swimming time was not statistically significant.

When Table 3 is analyzed, it is observed that the fat mass of upper extremity did not affect the cycling performance in terms of cycling time $(\mathrm{p}>0.05)$. While lean mass $(\mathrm{r}=0,073)$ and muscle mass $(\mathrm{r}=-$ $0,735)$ showed a negatively significant $(p<0.01)$ relationship, fat ratio $(\mathrm{r}=0,370)$ showed a positively significant relationship $(\mathrm{p}<0.05)$.

When Table 4 is analyzed, it is observed according to the regression analysis results that the results obtained for total race time are parallel with the results obtained for running and cycling times.

Table 1. Regression results illustrating the relationship between upper extremity segmental analysis results and running time

\begin{tabular}{|c|c|c|c|c|c|c|c|c|}
\hline \multicolumn{4}{|c|}{ Variables } & B & Standard error & Beta & $t$ & $\mathrm{p}$ \\
\hline \multirow{8}{*}{ Running Time } & & Fat Mass & & 2.957 & 5.670 & 0.081 & 0.522 & 0.605 \\
\hline & $\mathrm{R}=0.081$ & $\mathrm{R}^{2}=0.007$ & $\mathrm{~F}=0.272$ & $p=0.605$ & & & & \\
\hline & & Lean Mass & & -1.237 & 0.358 & -0.475 & -3.456 & $0.001^{* *}$ \\
\hline & $\mathrm{R}=0.475$ & $\mathrm{R}^{2}=0.226$ & $\mathrm{~F}=11.944$ & $p=0.001$ & & & & \\
\hline & & Fat Ratio & & 0.591 & 0.224 & 0.382 & 2.644 & $0.012^{* *}$ \\
\hline & $\mathrm{R}=0.382$ & $\mathrm{R}^{2}=0.146$ & $F=6.992$ & $p=0.012$ & & & & \\
\hline & & Muscle Mass & & -2.560 & 0.746 & -0.472 & -3.429 & $0.001^{* *}$ \\
\hline & $\mathrm{R}=0.472$ & $\mathrm{R}^{2}=0.223$ & $\mathrm{~F}=11.761$ & $p=0.001$ & & & & \\
\hline
\end{tabular}

Table 2. Regression results illustrating the relationship between upper extremity segmental analysis results and swimming time.

\begin{tabular}{|c|c|c|c|c|c|c|c|c|}
\hline & Vari & ables & & B & Standard error & Beta & $t$ & $p$ \\
\hline \multirow[t]{8}{*}{ Swimming Time } & & Fat Mass & & 125.161 & 452.018 & 0.043 & 0.277 & 0.783 \\
\hline & $\mathrm{R}=0.043$ & $\mathrm{R}^{2}=0.002$ & $\mathrm{~F}=0.077$ & $p=0.783$ & & & & \\
\hline & & Lean Mass & & 9.445 & 32.324 & 0.046 & 0.292 & 0.772 \\
\hline & $R=0.046$ & $\mathrm{R}^{2}=0.002$ & $\mathrm{~F}=0.085$ & $p=0.772$ & & & & \\
\hline & & Fat Ratio & & 6.264 & 19.209 & 0.051 & 0.326 & 0.746 \\
\hline & $R=0.051$ & $R^{2}=0.003$ & $F=0.106$ & $p=0.746$ & & & & \\
\hline & & Muscle Mass & & 21.002 & 67.253 & 0.049 & 0.312 & 0.756 \\
\hline & $R=0.049$ & $\mathrm{R}^{2}=0.002$ & $F=0.098$ & $p=0.756$ & & & & \\
\hline
\end{tabular}


Table 3. Regression results illustrating the relationship between upper extremity segmental analysis results and cycling time.

\begin{tabular}{|c|c|c|c|c|c|c|c|c|}
\hline & \multicolumn{3}{|c|}{ Variables } & $B$ & Standard error & Beta & $\mathrm{t}$ & $\mathrm{p}$ \\
\hline \multirow{8}{*}{ Cycling Time } & \multicolumn{3}{|c|}{ Fat Mass } & -4.349 & 7.429 & -0.091 & -0.585 & 0.561 \\
\hline & \multirow[t]{2}{*}{$R=0.091$} & $\mathrm{R}^{2}=0.008$ & $\mathrm{~F}=0.343$ & $\mathrm{p}=0.561$ & & & & \\
\hline & & Lean Mass & & -2.522 & 0.360 & -0.738 & -7.011 & $0.000^{*}$ \\
\hline & \multirow[t]{2}{*}{$R=0.738$} & $\mathrm{R}^{2}=0.545$ & $F=49.151$ & $\mathrm{p}=0.000$ & & & & \\
\hline & & Fat Ratio & & 0.751 & 0.295 & 0.370 & 2.457 & $0.015^{*}$ \\
\hline & \multirow[t]{2}{*}{$R=0.370$} & $\mathrm{R}^{2}=0.137$ & $F=6.487$ & $p=0.015$ & & & & \\
\hline & & Muscle Mas & & -5.225 & 0.753 & -0.735 & -6.941 & $0.000^{*}$ \\
\hline & $\mathrm{R}=0.735$ & $\mathrm{R}^{2}=0.540$ & $\mathrm{~F}=48.183$ & $\mathrm{p}=0.000$ & & & & \\
\hline
\end{tabular}

Table 4. Regression results illustrating the relationship between upper extremity segmental analysis results and total race time

\begin{tabular}{|c|c|c|c|c|c|c|c|}
\hline & \multicolumn{2}{|l|}{ Variables } & B & Standard error & Beta & $t$ & $p$ \\
\hline \multirow{8}{*}{ Total Race Time } & \multicolumn{2}{|l|}{ Fat Mass } & -2.955 & 13.724 & -0.034 & -0.215 & 0.831 \\
\hline & $\mathrm{R}=0.034 \quad \mathrm{R}^{2}=0.001$ & $F=0.046$ & $\mathrm{p}=0.831$ & & \multirow{3}{*}{-0.664} & \multirow{3}{*}{-5.680} & \multirow{3}{*}{$0.000^{* *}$} \\
\hline & Lean Mass & & -4.173 & \multirow[t]{2}{*}{0,735} & & & \\
\hline & $R=0.664 \quad R^{2}=0.440$ & $F=32.267$ & $p=0.000$ & & & & \\
\hline & Fat Ratio & \multicolumn{2}{|r|}{1.446} & \multirow[t]{2}{*}{0.538} & \multirow[t]{2}{*}{0.387} & \multirow[t]{2}{*}{2.686} & \multirow[t]{2}{*}{$0.010^{*}$} \\
\hline & $\mathrm{R}=0.387 \quad \mathrm{R}^{2}=0.150$ & $F=7.213$ & $p=0.010$ & & & & \\
\hline & Muscle Mass & & -8.645 & \multirow{2}{*}{1.534} & \multirow{2}{*}{-0.661} & \multirow[t]{2}{*}{-5.635} & \multirow[t]{2}{*}{$0.000^{* *}$} \\
\hline & $\mathrm{R}=0.661 \quad \mathrm{R}^{2}=0.436$ & $F=31.755$ & $p=0.000$ & & & & \\
\hline
\end{tabular}

\section{DISCUSSION}

In this study, which was conducted to investigate the relationship between the upper extremity fat masses and the race times of the triathletes, who competed in $9^{\text {th }}$ World University Triathlon Championship, it is observed that the upper extremity segmental analysis results did not affect the swimming time in triathlon ( $>0.05$ Table 2). It is also observed that the upper extremity fat mass did not have any effects on running, cycling and total race times ( $p>0.05$ Table 1, 3 and 4). It is also observed that upper extremity fat mass did not have any effect on running, cycling and total race times ( $p>0.05$; Table 1, 3 and 4 ).

According to the results obtained from various studies conducted on runners, it is known that the body fat affects performance. Excessive amount of subcutaneous tissue increases body mass, requires more muscular effort and therefore, the energy consumption increases $(21,24)$. The increase in fat mass, which is of no use in cyclists, creates a triple effect on performance decrease by increasing acceleration energy cost, rolling resistance, and the protruding surface area (9). In addition, there are various studies that show the negative relationship between physical performance and body fat $(2,21,24,25,26)$. The study conducted by Hetland et al. (12) reported that the performance results of treadmill test of the marathon runners showed negative correlation with local and total body fat.

It is observed in this study that the upper extremity fat mass did not have a significant effect on running, swimming, cycling and total race times. However, it is found at the end of the evaluations made with respect to fat ratio that the fat ratio shoved positive correlation with running, cycling and total race time. In other words, it can be concluded that an increase in upper extremity fat ratio causes extension of running, cycling and total race times and thus, performance decrease. While the results obtained on the upper extremity fat ratio are similar to other results in literature, the results obtained on fat mass are found to be incompatible with other results in literature.

It is found at the end of these studies that triathletes do not have any ideal or specific anthropometric profiles in terms of their performances (23) and that the exercise parameters are more important than anthropometric measurements to estimate performance $(3,4,6)$. Similarly, Hetland et al. (12) reported that various factors make significant contributions to body composition in different areas. It is also stated that the amount of exercise is a strong determinant of body compositions of legs and arms, however, the contribution of androgenic activity to abdominal fat ratio is very significant. In addition Knechtle et al. 
(18) stated that the race time is very important in correlation of skinfold thicknesses and race performance. In other words, as the race time extends, the extent to which the fat mass affects performance increases. However, in this study, the exercise profiles and durations of triathletes have not been determined and the athletes competed in Olympic distances. The studies in literature are generally conducted with fewer participants and ironman triathletes in longer distances $(3.8 \mathrm{~km}$ swimming, $180 \mathrm{~km}$ cycling and $42 \mathrm{~km}$ running). For these reasons, it can be concluded that results obtained from this study are not similar to the literature in terms of fat mass.

It is reported in various studies that physical performance shows a positive relationship with skeletal muscle mass and lean body mass $(5,13,21$ ,24,26). In another study, which was conducted on athletes that competed in a $338 \mathrm{~km}$ of race with five different stages that require excessive endurance, a positive relationship was observed between narrower upper arm circumference and performance. the same study also revealed that the lower levels of upper body muscle mass might be advantageous in terms of better performance times (17). When other studies in literature are reviewed, it is observed that the results obtained in terms of lean mass and muscle mass and their effects on performance were contradictory. In this study, a negatively significant relationship was observed between upper extremity lean mass and muscle masses and the running, cycling and total race times. in other words, it can be concluded that the race time decreases as the lean mass and muscle mass increase and this leads to an increase in performance. While the results for muscle mass and lean mass show similarities when compared to previous studies, it is observed that these results do not correspond to some other studies. The conflicting results of this study and some of the previous studies regarding upper extremity lean and muscle masses might result from the differences in race distances.

Consequently, it is observed in this study, which was conducted to investigate the relationship between upper extremity fat masses and race times of triathletes, that the upper extremity segmental analysis results did not affect swimming time, the upper extremity fat mass did not affect the running, cycling and total race times, but the upper extremity lean mass and muscle masses had a negatively significant relationship with running, cycling and total race times.

\section{REFERENCES}

1. Arrese AL, Ostáriz ES. Skinfold thicknesses associated with distance running performance in highly trained runners. Journal of Sports Sciences, 2006; 24(1): 69-76.

2. Ateş B, Saygın Ö, Zorba E. Evaluation of the physical capacity and the quality of life of the housewifes. International Journal of Human Science, 2009; 6(2): 357-367.

3. Bale $\mathrm{P}$, Rowell S, Colley E. Anthropometric and training characteristics of female marathon runners as determinants of distance running performance. J Sports Sci, 1985; 3: 115-126.

4. Bale P, Bradbury D, Colley E. Anthropometric and training variables related to $10 \mathrm{~km}$ running performance. Br J Sports Med, 1986; 20: 170-173.

5. Boileau RA, Horswill CA. Body composition in sports: Measurement and applications for weight loss and gain. Exercise and sport science (Ed. W.E, Garrett, D.T., Kirkendall)'de, Lippincott Williams and Wilkins, Philadelphia, USA, 2002; 319-338.

6. Christensen CL, Ruhling RO. Physical characteristics of novice and experienced women marathon runners. Br J Sports Med, 1983; 17: 166-171.

7. Docherty D, Gaul CA. Relationship of body size physique and composition to physical performance in young boys and girls. Int J Sports Med, 1991; 12: 525-532.

8. Geladas ND, Nassis GP, Pavlicevic S. Somatic and physical traits affecting sprint swimming performance in young swimmers. Int J Sports Med, 2005; 26: 139-144.

9. Gregor RJ. Biomechanics of Cycling. In: Garrett WE, Kirkendall DT, editors. Exercise and Sport Science. Philadelphia (PA): Lippincott Williams and Williams, 2010; 515-537.

10. Gregory J, Johns DP, Walls JT. Relative vs. absolute physiological measures as predictors of mountain bike crosscountry race performance. J Strength Cond Res, 2007; 21: 1722.

11. Hagan RD, Upton SJ, Duncan JJ, Gettman LR. Marathon performance in relation to maximal aerobic power and training indices in female distance runners. Br J Sports Med, 1987; 21: 3-7.

12. Hetland ML, Haarbo J, Christiansen C. Regional body composition determined by dual-energy X-ray absorptiometry. Relation to training, sex hormones, and serum lipids in male long-distance runners. Scandinavian Journal of Medicine and Science in Sports, 1998; 8: 102-108.

13. Heyward VH, Stolarczyk LM. Applied Body Composition Assessment. Champaign, IL; Human Kinetics, USA, 1996.

14. Hoffman MD, Lebus DK, Ganong AC, Casazza GA, Van Loan M. Body composition of 161-km ultramarathoners. Int J Sport Med, 2010; 31: 106-109.

15. Impellizzeri FM, Rampinini E, Sassi A, et al. Physiological correlates to off-road cycling performance. J Sports Sci, 2005; 23: 41-47.

16. Knechtle B, Duff B, Schulze I, Rosemann T, Senn O. Anthropometry and pre-race experience of finishers and 
nonfinishers in a multistage ultra-endurance runDeutschlandlauf 2007. Perceptual and Motor Skills, 2009; 109: 105-118.

17. Knechtle B, Duff B, Welzel U, Kohler G. Body mass and circumference of upper arm are associated with race performance in ultraendurance runners in a multistage race the Isarrun 2006. Res Q Exerc Sport, 2009; 80: 262-268.

18. Knechtle B, Knechtle P, Andonie JL, Kohler G. Influence of anthropometry on race performance in extreme endurance triathletes: World Challenge Deca Iron Triathlon 2006. Br J Sports Med, 2007; 41: 644-648.

19. Knechtle B, Knechtle P, Barandun U, Rosemann T. Anthropometric and training variables related to halfmarathon running performance in recreational female runners. The Physician and Sportsmedicine, 2011; 39(2): 158 166.

20. Knechtle B, Knechtle P, Schulze I, Kohler G. Upper arm circumference is associated with race performance in ultraendurance runners. Br J Sports Med, 2008; 42(4): 295-299.

21. Knechtle B, Kohler G. Running performance, not anthropometric factors, is associated with race success in aTriple Iron Triathlon. Br J Sports Med, 2009; 43: 437-441.

22. Knechtle B, Wirth A, Rüst CA, Rosemann T. The relationship between anthropometry and split performance in recreational male ironman triathletes. Asian Journal of Sports Medicine, 2011; 2(1): 23-30.

23. Laurenson NM, Fulcher KY, Korkia P. Physiological characteristics of elite and club level female triathletes during running. Int J Sports Med, 1993; 14: 455-459.
24. Leedy HE, Ismail AH, Kessler WV et al. Relationship between physical performance items and body composition. Res Q Exerc Sport, 1965; 36: 158-163.

25. Norton KI, Olds T, Olive S, et al. Anthropometry and sports performance. In: Norton KI, Olds $\mathrm{T}$, editors. Anthropometrica. Sydney: University of New South Wales Press, 1996: 289-364.

26. Riedenau RP, Welch BE, Crips CE, et al. Relationship of body fat to motor fitness test scores. Res Q Exerc Sport, 1968; 29: 200-203.

27. Siders WA, Lukaski HC, Bolonchuk WW. Relationships among swimming performance, body composition and somatotype in competitive collegiate swimmers. J Sports Med Phys Fitness, 1993; 33: 166-171.

28. Swain DP. The influence of body mass in endurance bicycling. Med Sci Sports Exerc, 1994; 26: 58-63.

29. Tanaka K, Matsuura Y. A multivariate analysis of the role of certain anthropometric and physiological attributes in distance running. Annals of Human Biology, 1982; 9: 2.

30. Tuuri G, Loftin M, Oescher J. Association of swim distance and age with body composition in adult female swimmers. Med Sci Sports Exerc, 2002; 34: 2110-2114.

31. Zampagni ML, Casino D, Benelli P, et al. Anthropometric and strength variables to predict freestyle performance times in elite master swimmers. J Strength Cond Res, 2008; 22: 12981307. 